Authors version of:

"Ruju, A., Conley, D.C., Masselink, G., Puleo, J., 2016. Sediment transport dynamics in the swash zone under large-scale laboratory conditions. Continental Shelf Research, 120, 1-13. http://dx.doi.org/10.1016/j.csr.2016.03.015" 


\title{
Sediment transport dynamics in the swash zone under large-scale laboratory conditions
}

\author{
Andrea Ruju ${ }^{\mathrm{a}}$, Daniel Conley ${ }^{\mathrm{a}}$, Gerd Masselink ${ }^{\mathrm{a}}$, Jack Puleo ${ }^{\mathrm{b}}$ \\ ${ }^{a}$ School of Marine Science and Engineering, Plymouth University, Drake Circus, \\ Plymouth, Devon, PL8 4AA, UK \\ ${ }^{b}$ Center for Applied Coastal Research, University of Delaware, Newark, DE 19716, USA
}

\begin{abstract}
A laboratory experiment was carried out to study sediment transport dynamics occurring in the swash zone of a coarse-sandy beach built in a large-scale wave flume. Hydro- and morpho-dynamic as well as sediment transport data were collected using sensors mounted on a scaffold rig deployed in the lower swash zone close to the moving bed. The high resolution of near-bed data permitted quantitative evaluation of suspended and sheet flow contributions to the total sediment transport. Although sheet flow sediment fluxes were higher than suspended fluxes, the vertically integrated suspended sediment load overcame the sheet flow load during uprush and it was on the same order of magnitude during backwash. The observed cumulative sediment transport was generally larger than the morphological changes occurring shoreward of the rig location implying either an underestimation of the offshore sediment transport or an overestimation of the onshore fluxes obtained from concentration and velocity profile data. Low correlations were found between net swash profile changes and runup parameters suggesting that local hydrodynamic parameters provide little or no predictability of accretion and erosion of an upper beach which is near equilibrium. The balance between erosion and deposition induced by individual swash events brought a dynamic equilibrium with small differences between the profiles measured at the start and at the end of the run.
\end{abstract}

Keywords:

Swash, Sediment transport, Sheet flow, Suspended transport

Email address: daniel.conley@plymouth.ac.uk (Daniel Conley) 


\section{Introduction}

Incoming swell waves induce sediment transport fluxes which are particularly intense in shallow waters eventually leading to morphological beach changes. Under wave forcing, the shoreline position evolves as a consequence of swash hydrodynamic processes which enable a sediment exchange between the submerged and the emerged regions of the beach (Masselink and Hughes, 1998). The shallow, rapid, turbulent and aerated flows in the swash zone bring large sediment concentrations within the water column leading to large suspended sediment transport rates (Elfrink and Baldock, 2002; Masselink and Puleo, 2006). In addition, near-bed sediment transport contributes to the total swash zone sediment transport.

The intense near-bed sediment transport observed in the swash zone is induced by advection from the surf zone and by large bed shear stresses resulting in a flattening of the bed which does not present the typical surf zone bedforms (Bagnold, 1956; Nielsen, 1992). Whereas the mobilizing mechanism of the suspended transport is flow turbulence, under sheet flow conditions intergranular collisions become the primary agent for sediment suspension (Hsu et al., 2004). Sheet flow is usually observed in the nearshore on the crest of sandbars (Nielsen, 1992) and in the swash zone (Masselink and Puleo, 2006). Horn and Mason (1994) showed that the large sediment rates which characterize sheet flows play a significant role in the overall swash zone sediment transport budgets.

A large number of studies dealing with sediment transport in the swash zone focused the attention on suspended load (Puleo et al., 2000; Masselink et al., 2005; Caceres and Alsina, 2012). On the other hand, the improvement in the understanding of sheet flow processes (inside and outside the swash zone) has progressed slowly due to the scarcity of detailed measurements which have been mainly provided by oscillatory flow tunnel experiments (O'Donoghue and Wright, 2004; van der A et al., 2010). Recently, Lanckriet et al. (2013) and Lanckriet et al. (2014) developed a new CCP sensor to measure the vertical profile of sediment concentration within the sheet flow layer. Puleo et al. (2015) and Puleo et al. (2014) performed an analysis of CCP data yielding important insights into sheet flow processes with unprecedent detail. These studies highlighted the relative importance of sheet flow sediment transport especially during backwash phase of swash and investigated the bed level changes induced by individual swash events. At the same time they warned about the limitation associated with the temporal 
gaps in data collection which can potentially lead to an artificial truncation of the backwash.

The objective of this work is to use the near-bed flow velocity and concentration measurements obtained through the large scale laboratory experiments BARDEX II to investigate sediment transport processes and morphological changes in the swash zone. In particular, the individual contribution of suspended and sheet flow sediment transport are highlighted and the relationship between hydrodynamics and profile changes are studied. The paper is structured as follows. Section 2 describes the laboratory experiments and the analysis technique used in this work. The results with relative discussion are presented in section 3 and 4 . Section 5 provides the main conclusions.

\section{Methods}

\subsection{Laboratory Experiments}

The BARDEX II experiment was carried out in the Delta flume, The Netherlands, to study nearshore processes in the presence of a sandy beach backed by a lagoon (Masselink et al., 2015). The Delta flume is $200 \mathrm{~m}$ long, $5 \mathrm{~m}$ wide and $7 \mathrm{~m}$ high; waves are generated by hydraulically-driven pistontype wave maker located at one end of the flume. A relatively coarse sandy beach (median grain diameter of $0.43 \mathrm{~mm}$ ) $4.5 \mathrm{~m}$ high backed by a lagoon was built in the flume. The beach slope before the wave action was 1:15 and the still water depth at the wave maker position was set to $3 \mathrm{~m}$. A permeable wall separated the sandy barrier from the lagoon. The coordinate system was established with the horizontal axis $x$ increasing onshore and the vertical $z$ axis increasing upward. Swash hydrodynamics and sediment concentrations were collected by sensors mounted on a scaffold rig deployed in the swash zone. Different runs were performed with significant wave height ranging between 0.4 and $1 \mathrm{~m}$ and and peak period ranging between 4 and 12 s. This paper presents data from the 1-hour-long irregular-wave run A2_05 characterized by a significant wave height $H_{s}$ of $0.8 \mathrm{~m}$ and peak period $T_{p}$ of 8 s. A minimal change of the beach profile and the total amount of sediment in the swash zone $\left(0.005 \mathrm{~m}^{3} / \mathrm{m}\right)$ was observed during the run. Taking advantage of the fact that sheet flow probes are not rapidly buried or exposed during the run A2_05, it has been specifically chosen as representative of a dynamic equilibrium configuration in which the beach does not experience significant erosion or deposition over a long time scale. The wave action steepened the beach face in the previous runs yielding a beach slope of 0.09 which 
showed little variability during run $A 2 \_05$. The measurements analysed in this paper derive from the central swash rig where sensors were submerged for a relatively high portion of time and the sensor configuration allowed a high vertical resolution across the water column.

The horizontal components $(\mathrm{u}, \mathrm{v})$ of flow velocity within the water column were measured by 2 Valeport EletroMagnetic Current Meters (EMCM) separated by $0.03 \mathrm{~m}$ in the vertical direction and deployed approximately 0.05 and $0.08 \mathrm{~m}$ from the bottom. The 3 components $(\mathrm{u}, \mathrm{v}, \mathrm{w})$ of the nearbed velocity profile with a vertical resolution of $0.001 \mathrm{~m}$ up to $0.03 \mathrm{~m}$ above the sandy bottom were collected using a Nortek Acoustic Doppler Velocity Profiler (ADVP). A Bed Level Sensor (BLS) array recorded the fluctuations of the water free surface and the exposed bed in the swash zone with a horizontal spatial resolution of approximately $0.7 \mathrm{~m}$. EMCM, ADVP and BLS data were recorded at 6.100 and $4 \mathrm{~Hz}$. respectivelv.
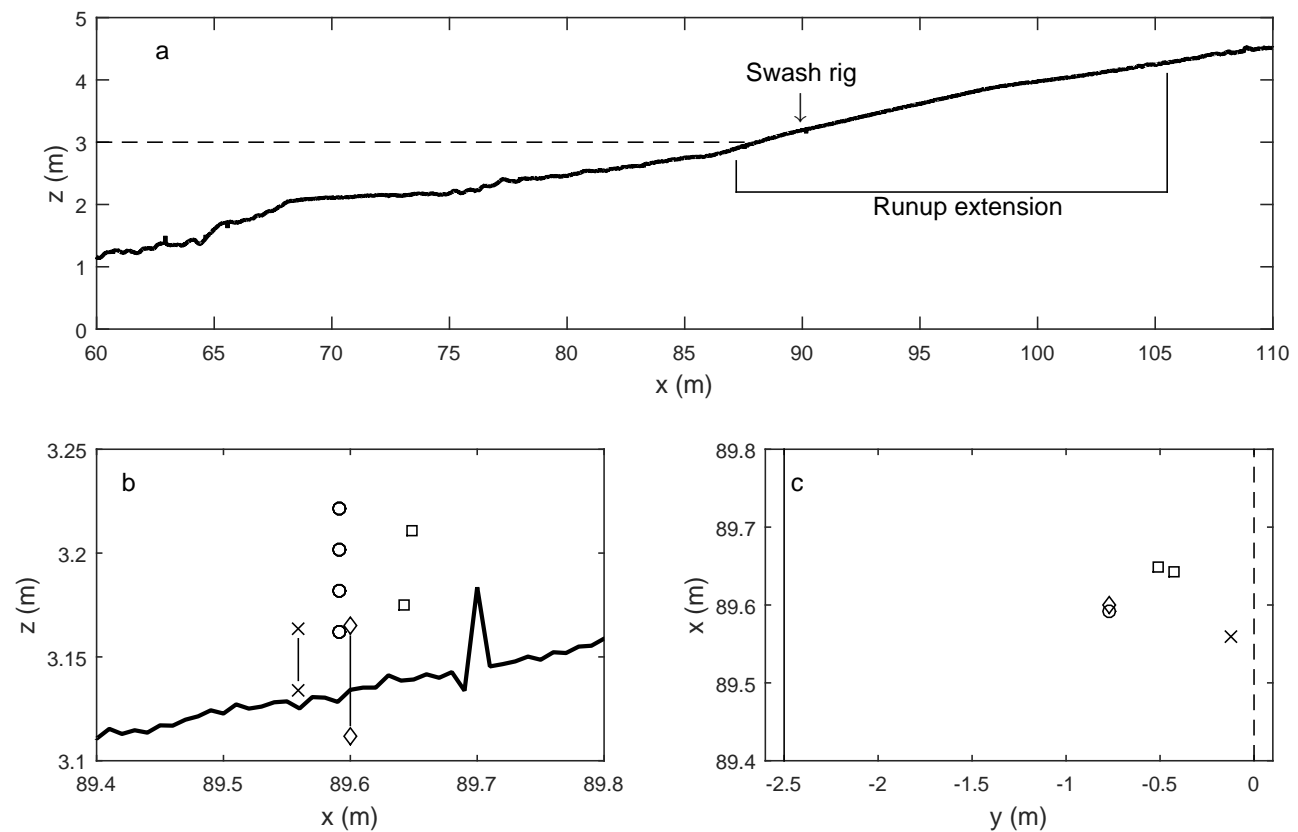

Figure 1: Beach profile and instrumentation. a) beach profile. The dashed line represents the still water level. The arrow indicates the swash rig location. b) and c) Volume sampling locations. Crosses: ADVP; squares: EMCM; diamonds: CCP; circles: OBS. In b) the solid line represents the beach profile. In c) the solid and dashed lines indicate the side and the center of the flume, respectively. 
Two different types of sensors collected suspended and sheet flow sediment concentrations. Suspended sediment concentrations (SSC) were measured by 4 Campbell Scientific Optical Backscatter Sensors (OBS) separated by 0.02 $\mathrm{m}$ in the vertical direction. OBS were deployed approximately from 0.04 to $0.1 \mathrm{~m}$ above the sandy bottom covering the same vertical range as the EMCM. Concentrations were sampled by OBS at $16 \mathrm{~Hz}$. Near-bed sediment concentration profiles were measured by 3 partially-overlapping Conductivity Concentration Profilers (CCP) designed at the University of Delaware (Lanckriet et al., 2013, 2014). Each CCP provided a spatial resolution of $0.001 \mathrm{~m}$ over a range of $0.029 \mathrm{~m}$. The upper sensor was buried with only a small sampling portion exposed to the flow with the aim to cover the active sheet layer and detect the bed location. CCPs were sampled at $8 \mathrm{~Hz}$. Figure 1 shows the beach profile with the location of the swash rig and the instrumentation. A picture of the sensors mounted on the swash rig is displayed in figure 2 .

\subsection{Data analysis}

The nature of swash dynamics represents a challenge for an accurate collection of hydro and morphological experimental observations (Hughes et al., 1997). Swash flows are intermittent by definition; moreover, gaps in time series measurements exist due to instrument limitations (Puleo et al., 2014). Noise in EMCM data is likely to occur when the transducers are hit by the incoming bore. ADVP data present the same issue and they have an additional drawback represented by turbulent bubbly flows. Here, EMCM, ADVP, CCP and OBS time series data were retained only during the portions of time in which the control volume of the relevant sensor was submerged. EMCM, CCP and OBS time series required no additional treatment but ADVP measurements needed additional filtering to remove flow data when at least one of the two following circumstances occurred (Aagard and Hughes, 2006; Puleo et al., 2012): 1) the instantaneous (averaged over the four beams) Correlation (Corr) values were less than $65 \% ; 2$ ) the instantaneous (averaged over the four beams) Signal-to-Noise-Ratio (SNR) values dropped below 20. These criteria have been chosen to remove unreliable data associated with airentrainment, bubbles and large sediment concentrations. Finally, additional noise and spurious data points were eliminated from the ADVP velocity time series by using the despiking method proposed by Mori et al. (2007).

In addition to temporal gaps due to instrument recording limitations, spatial measurement gaps are likely to occur due to the difficulty in obtaining 


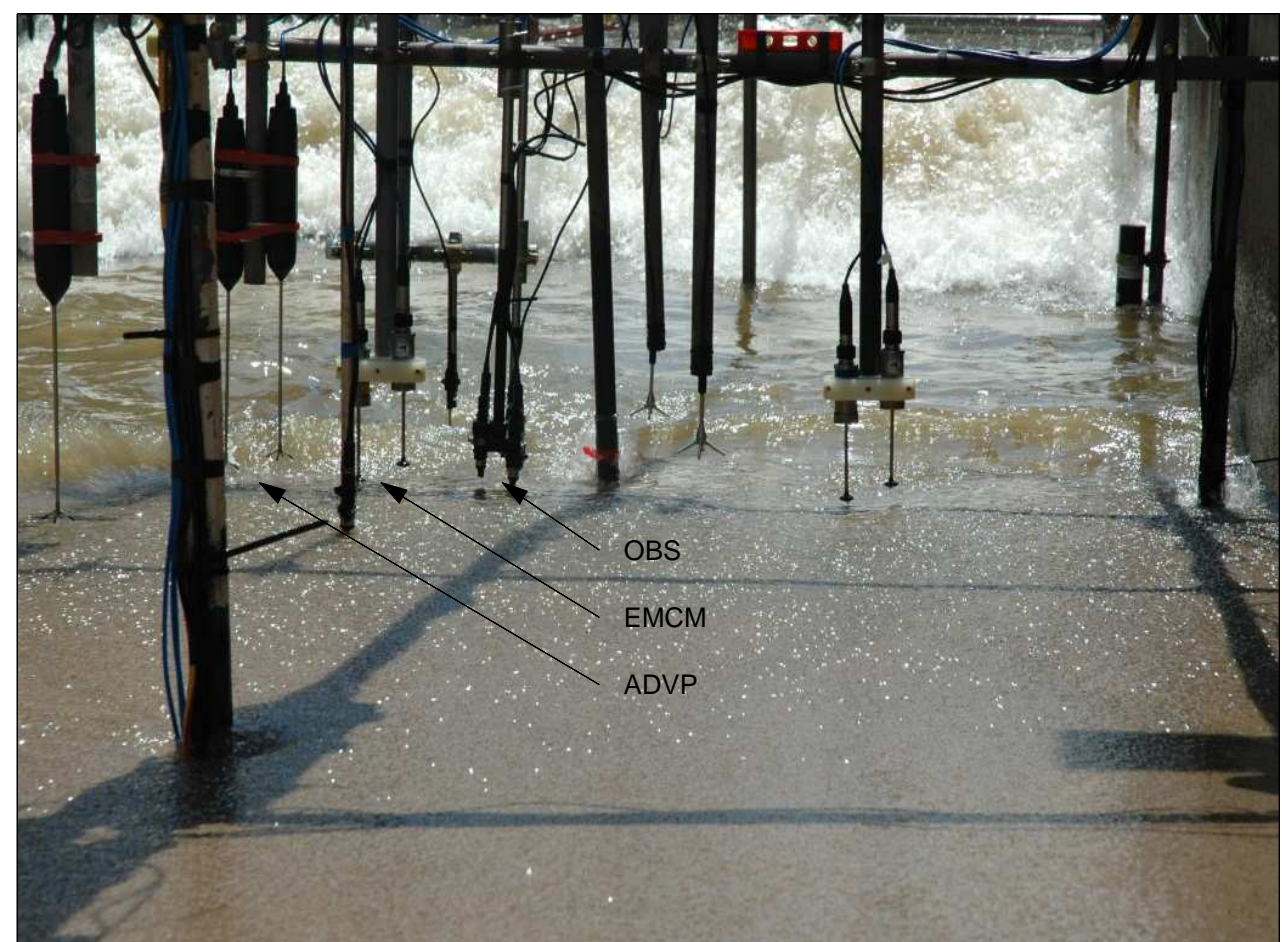

Figure 2: Picture of the relevant instrumentation on the swash scaffold rig. The arrows indicate the sensors used in this work: ADVP, EMCM and OBS. The CCP are buried and are not visible here. 
a complete instrument coverage of the vertical profile. The following interpolation procedures were applied in order to extend velocity measurements across the flow field. Velocities from the EMCM and ADVP were linearly interpolated through the water column. For the time instants in which a gap exists between the lowest flow data measured either by EMCM or ADVP and the top of the sheet flow layer, the velocity profiles in this region were reconstructed by assuming a logarithmic shape extending between the lowest velocity measurement and the zero-velocity bottom of the sheet flow layer. A linear velocity profile was assumed to extend from the top of the sheet flow layer, where the velocity can be either measured by ADVP or reconstructed using the logarithmic profile, to the bed level, where a zero velocity is considered. A similar procedure was adopted for the concentration data that were linearly interpolated over the region covered by the OBS measurements. No extrapolation was carried out in the region above the highest OBS location which inevitably leads to the exclusion of the upper water column region from the present analysis. An exponential profile according to the Rouse curve was used to fill the gap between the lowest OBS and the location of the top of the sheet flow layer detected by the CCP. As a result, $\mathrm{CCP}$ data above the sheet flow layer were replaced by the theoretical curve and therefore not considered, mainly due to the difficulties of CCP in the detection of relatively small concentrations $\left(<0.08 \mathrm{~m}^{3} / \mathrm{m}^{3}\right)$ within the water column. Alternatively to the Rouse profile, this spatial gap could have been filled by imposing a constant concentration profile equal to the concentration measured by the lowest OBS. The adoption of such procedure in this work leads to slightly smaller suspended sediment fluxes in the proximity of the top of the sheet flow layer but does not alter significantly the loads. Figure 3 shows the velocity and concentration measurements recorded at a determined instant and their respective interpolated values.

Similar to previous sheet flow sediment transport studies (O'Donoghue and Wright, 2004; Puleo et al., 2014), we identified the location of the top of the sheet flow layer as the elevation where the CCP recorded a sediment concentration $c$ equal to $0.08 \mathrm{~m}^{3} / \mathrm{m}^{3}$ (Bagnold, 1956). The boundary between the sheet flow layer and the non-moving sediment bed was determined as the location where the concentration measured by CCP was $0.51 \mathrm{~m}^{3} / \mathrm{m}^{3}$ which represents the loose packing limit for natural beach sand. The CCP data showed a sharp shoulder transition in the sediment concentration profiles between the lower sheet flow layer and the non-moving sediment, consistent with the experiments of O'Donoghue and Wright (2004), Dohmen-Janssen 
and Hanes (2005) and Lanckriet et al. (2014). In order to obtain more reliable detections of the sheet flow layer boundaries, we used the curvefitting method to define the bottom of the sheet flow layer by extending the the linear portion of the sheet flow concentration profile (Pugh and Wilson, 1999; O'Donoghue and Wright, 2004; Lanckriet et al., 2014). The timevarying sheet flow thickness was defined as the vertical distance between the top and the bottom of the sheet flow layer.
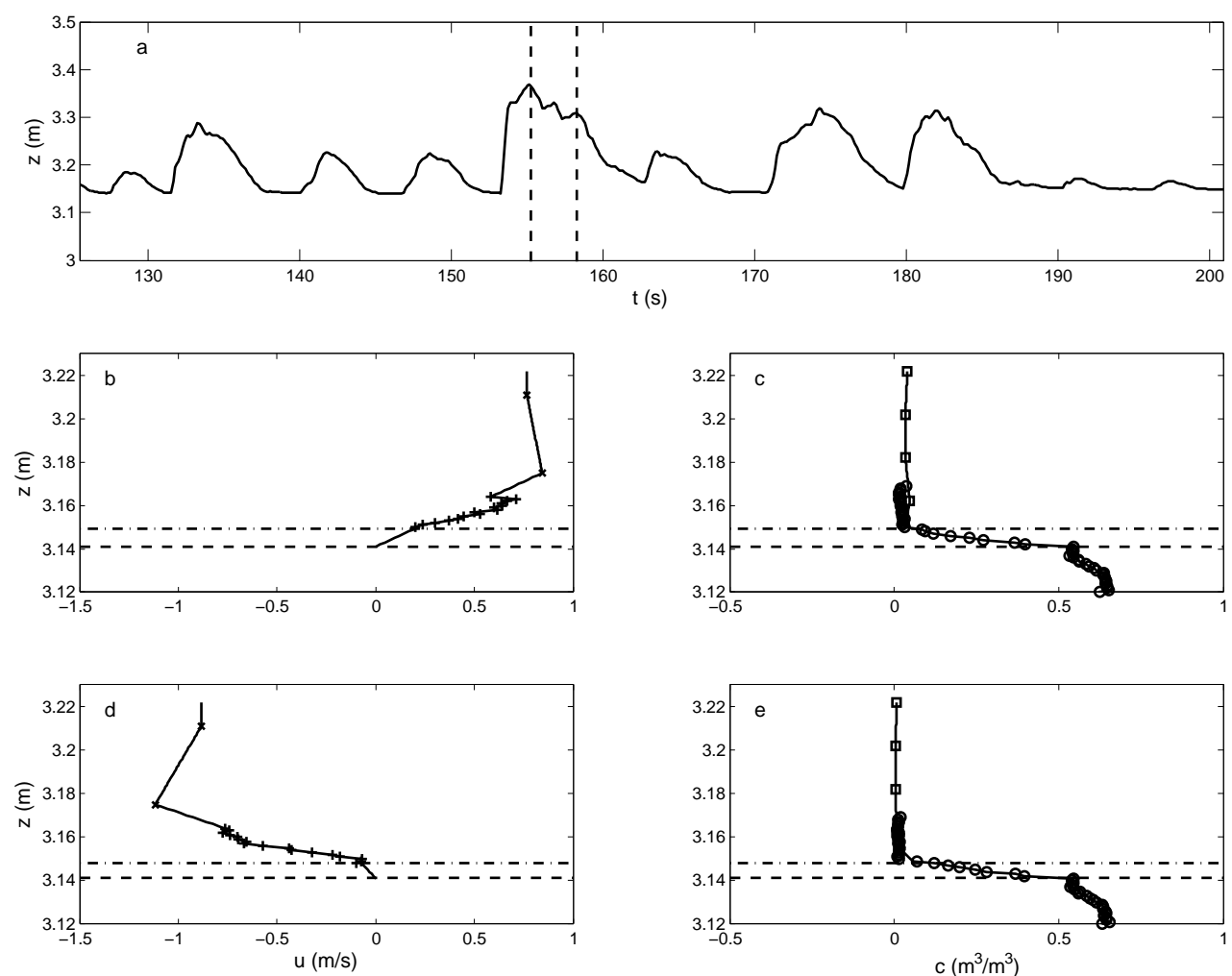

Figure 3: Spatial interpolation of velocity and concentration measurements. a) Time series of free surface; the vertical dotted lines indicate the time instants considered in the other panels. Velocity measurements (symbols) and interpolation (solid line) for uprush (b) and backwash (d). Sediment concentration measurements (symbols) and interpolation (solid line) for uprush (c) and backwash (e). Horizontal dashed lines represent the top and bottom of the sheet flow layer. 


\section{Results}

\subsection{Hydrodynamics and bed fluctuations}

Spectral analysis of the swash zone is traditionally considered a difficult task due to the intermittent nature of swash processes (Elfrink and Baldock, 2002). Puleo et al. (2014) have overcome the lack of continuous time series by applying linear interpolation in order to fill the temporal gaps in the velocity measurements. In this work, we perform spectral analysis on the bed level elevation detected by the CCP and water depth elevation detected by the BLS at the swash rig location. The time series of the bed level elevation is continuous and does not require any assumption or treatment. On the other hand, since the BLS measured either the free surface elevation during submergence and the bed level during emergence, temporal gaps in the water depth are filled by assuming that the water level coincides with the bed level elevation when the backwash has already cleared the beach and the bed is exposed.

Example of time series of bed level elevation and water depth at the swash rig position $(x=89.6 \mathrm{~m})$ with the relative energy spectra are shown in figure 4. The spectral estimates of the water depth are obtained from Fourier transforms of $1024 \mathrm{~s}$ long segments with $50 \%$ overlap smoothed by merging 3 frequency bands leading to a final frequency resolution of 0.003 $\mathrm{Hz}$; the number of degrees of freedom is 18 and the $95 \%$ confidence intervals are plotted in the figure. The water depth spectrum presents a secondary peak close to the location of the incoming frequency peak indicated by a vertical dotted line (the peak in the spectrum is at $0.12 \mathrm{~Hz}$ whereas the incoming wave peak frequency is $0.125 \mathrm{~Hz}$ ); however, the dominant peak is located at $0.034 \mathrm{~Hz}$ in the infragravity band $\left(f<0.5 f_{p}\right)$ which brings a significant contribution ( $55 \%$ ) to the total variance. On the other hand, the bed level elevation spectrum is strongly dominated by low-frequency motion (95\% of the total variance in the infragravity band) characterized by large fluctuation with periods larger than $256 \mathrm{~s}$. The bed level spectrum shows a slope proportional to $f^{-2}$ extending over the high-frequency band from the peak frequency of the incoming wave field, whereas the depth spectrum presents a slightly steep spectral roll off on the order of $f^{-3}$.

Figure 5 shows the squared coherence and phase between the free surface elevation and the bed level fluctuations determined by cross-spectral analysis. The cross-spectral estimates are obtained by using the same parameters used for the spectral estimates. Squared coherence is considered significant for 

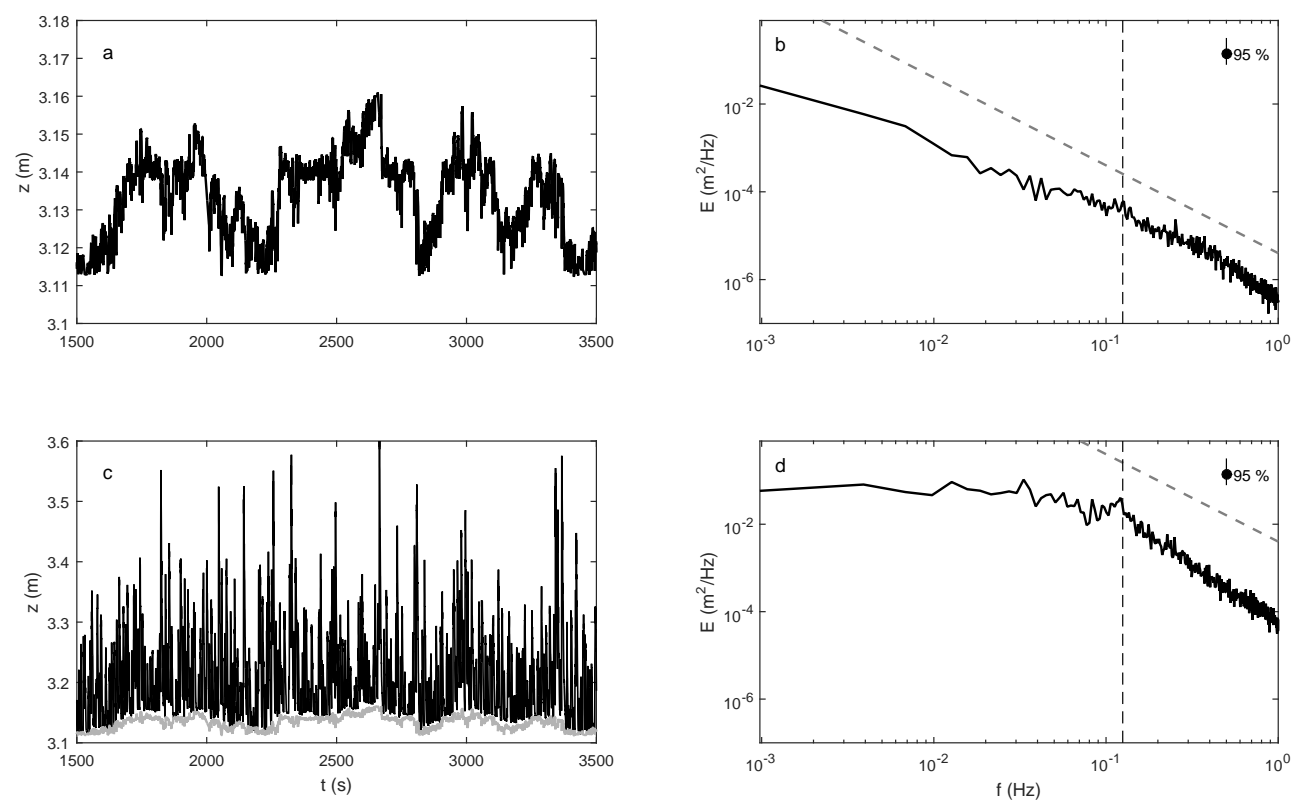

Figure 4: Time series (a) and spectra (b) of bed level elevation. Time series (c) and spectra (d) of water depth. The grey line in (c) is the bed level elevation. The vertical dashed line indicates the peak frequency of the incoming waves. The dashed lines in (b) and (d) show a $f^{-} 2$ slope for reference. 
those frequencies in which it exceeds the $95 \%$ confidence limit indicated by the horizontal dashed line in figure 5b. Phases are plotted in figure $5 \mathrm{a}$ when coherence is significant. Significant coherence is found in the frequency band comprised between 0.12 and $1.125 \mathrm{~Hz}$ in which the incident energy peak is observed in the free surface elevation spectrum (figure $4 \mathrm{~d}$ ). For the same frequency band and also for higher frequencies, the phases are generally positive and close to $\pi$ implying that the bed fluctuations are in antiphase with the forcing represented by the free surface elevation. For frequencies lower than the frequency peak including infragravity frequencies, the phase tends to shift from negative to positive values for increasing frequencies. The negative phases observed for very low frequencies $(f<0.05 \mathrm{~Hz})$ indicate that the free surface laoss the hed level elevation.
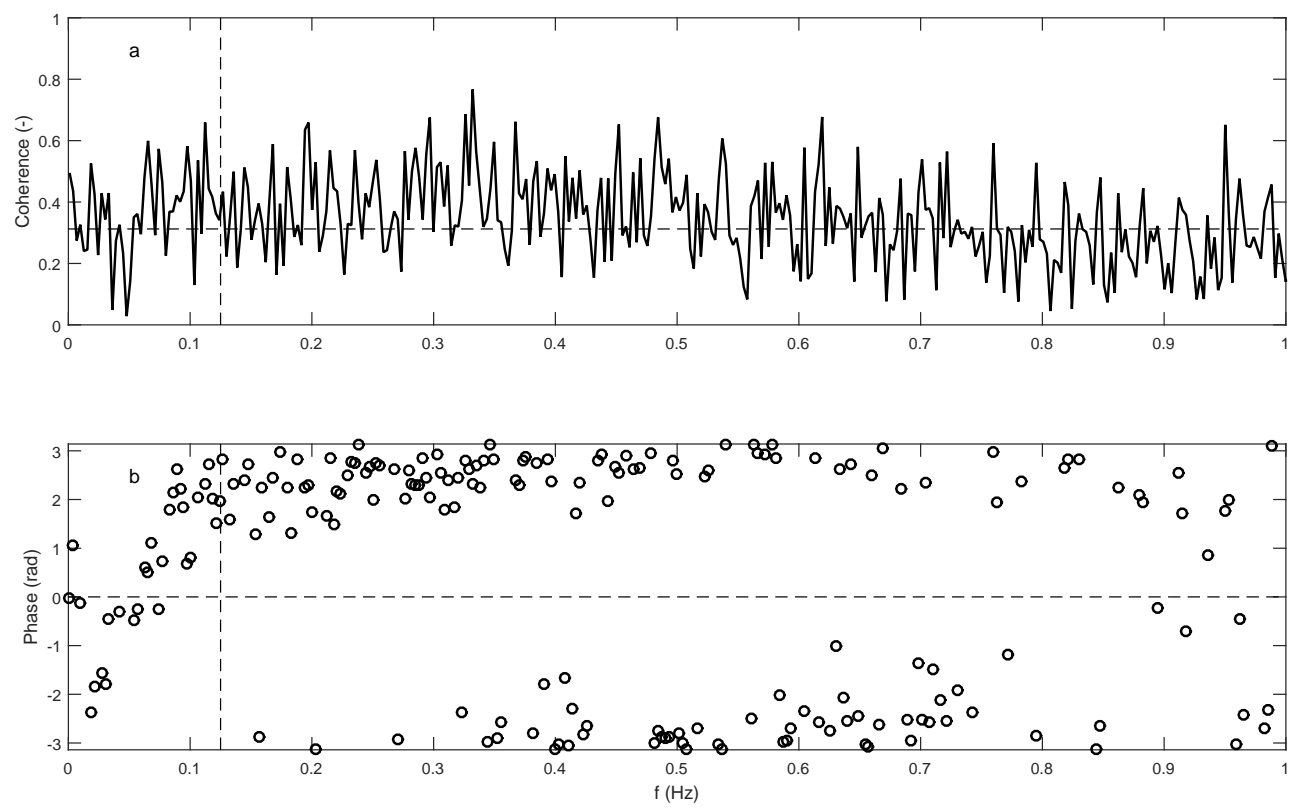

Figure 5: Cross-spectral estimates for free surface elevations and bed level fluctuations. Squared coherence (a) and phase (b). The vertical dashed line indicate the peak frequency of the incoming wave field. The horizontal dashed line in (a) is the $95 \%$ confidence limit.

\subsection{Hydrodynamics and sediment transport}

Figure 6 shows the time series of free surface displacement and cross-shore velocity at different elevations measured by the BLS and ADVP, respectively. 
Water depth is on the order of $0.4 \mathrm{~m}$ for largest events occurring at around $3400 \mathrm{~s}$ from the start of the run. The bed usually becomes dry between small events indicating that the interaction of backwashes with the successive uprushes is small and takes place further offshore of the swash rig. On the other hand, backwashes associated with large events can be truncated by incoming uprush (see around $3400 \mathrm{~s}$ ) with water depths that do not go to zero causing low-frequency traces in the spectra (see figure 4). Cross-shore velocities at the highest ADVP sampling location are in the range between 1.5 and $-1.8 \mathrm{~m} / \mathrm{s}$. Velocities decrease towards bed as result of boundary layer effects (Ruju et al., 2015). Velocity signal at the lowest ADVP sampling location are minimal because of the presence of the bed. However, for the 2 events after $3430 \mathrm{~s}$ in figure $6 \mathrm{~b}$, velocities at the lowest ADVP sampling location are similar to those measured further upward indicating that they are likely to be measured above the boundary layer as the bed drops downward outside the range of the ADVP.
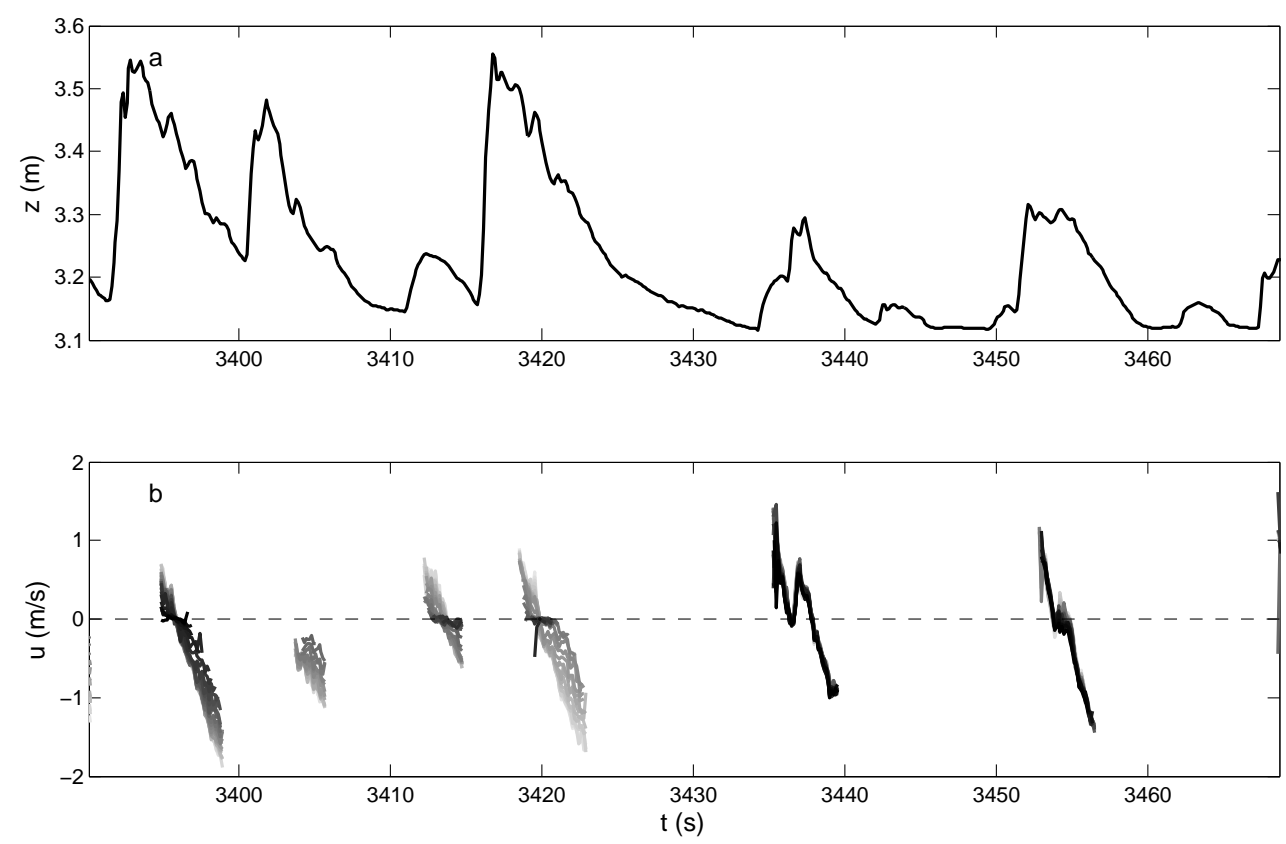

Figure 6: Time series of free surface displacement (a). Cross-shore velocity from ADVP at different elevations (b): the lighter the color the higher the elevation

Several studies dealing with swash hydrodynamics proposed a bottom 
identification method based on the velocity profile in order to overcome the lack of near-bed sediment concentration measurements (Puleo et al., 2012; Ruju et al., 2015). A common practice has been to define the bottom (for individual swash events) as the vertical location where the standard deviation of velocity reaches a threshold value. In this study, the bed location inferred using the velocity profile obtained by the ADVP (standard deviation of velocity equal to $0.05 \mathrm{~m} / \mathrm{s}$ ) roughly corresponds with the top of the sheet flow layer during flow reversal detected by the CCP (not shown). This appears to be related to the difficulties that ADVP sensors experience when they operate in a high sediment concentration environment such as the sheet flow layer. Moreover, the bed drop events cause the spatial coverage of the ADVP to lie above the sheet flow layer (after $3430 \mathrm{~s}$ ).
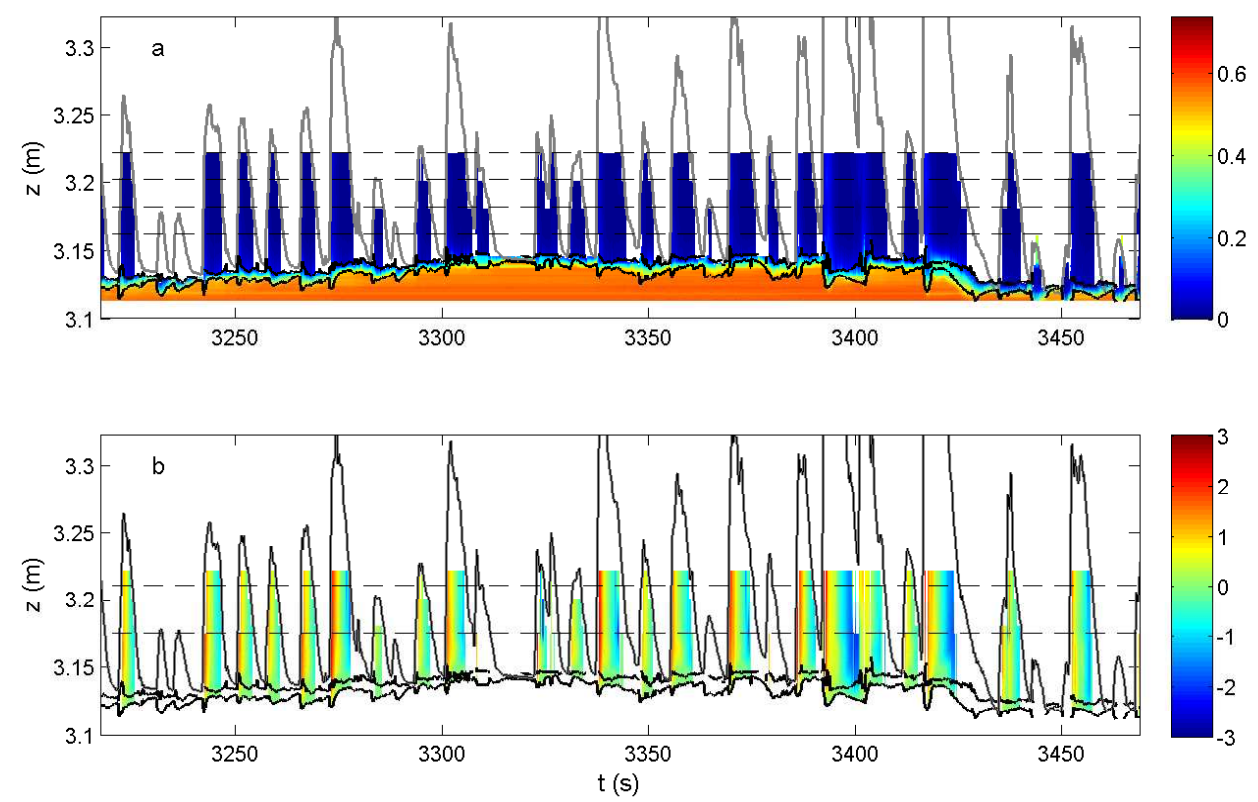

Figure 7: Time series of sediment concentration in $\mathrm{m}^{3} / \mathrm{m}^{3}$ (a) and velocity in $\mathrm{m} / \mathrm{s}$ (b) profiles. Black solid lines indicate the bottom and the top of the sheet flow layer. Horizontal black dashed lines indicate the OBS (a) and EMCM (b) vertical locations. The free surface displacement is indicated by a solid grey line.

Figure 7 shows hydro- and morhphodynamic parameters at the swash station. Figure 7 a shows the time series of sediment concentration profiles 
recorded between the lowest $\mathrm{CCP}$ and the highest OBS; the fluctuations of the bottom and the top of the sheet flow layer are indicated by solid black lines. Velocity collected by ADVP and EMCM are shown in figure 7b. Relatively high velocities (larger then $1.5 \mathrm{~m} / \mathrm{s}$ ) occur in the water column at the beginning of uprush and a the end of the backwash. The sheet flow layer at this swash location responds to the hydrodynamic forcing showing oscillations at the incident wave time-scale. The bed level experiences a slow increase of the order of few cm between 3200 and $3300 \mathrm{~s}$, then it stays almost stable for about $100 \mathrm{~s}$ and finally it decreases following the energetic events occurring between 3400 and 3430 s. After 3440 s the bed falls below the spatial coverage of the CCP.
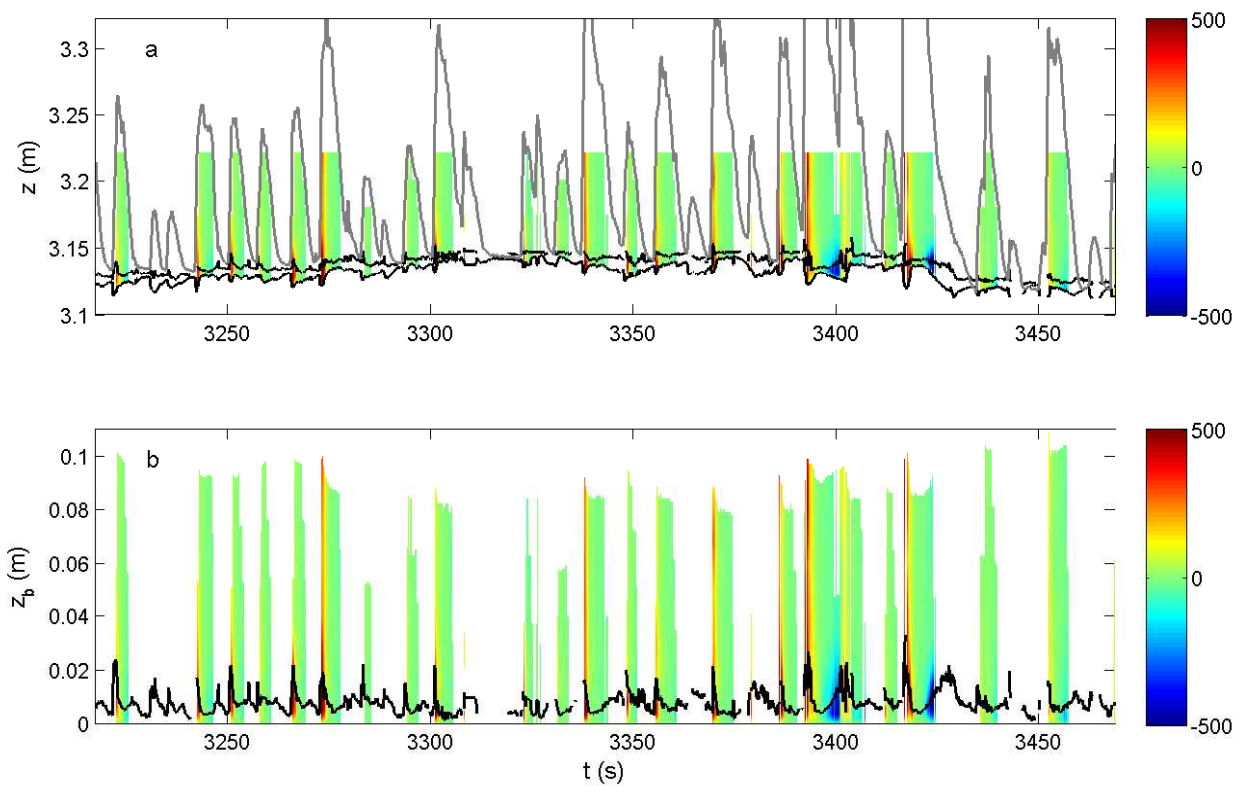

Figure 8: Time series of sediment transport fluxes profiles in $\mathrm{Kg} /\left(\mathrm{m}^{2} \mathrm{~s}\right)$ with vertical coordinate system $z$ (a) and $z_{b}$ (b) for which the fluctuating origin has been defined as the bottom of the sheet flow layer. Black solid lines indicate the bottom and the top of the sheet flow layer. The free surface displacement is indicated by a solid grey line in (a).

Cross-shore sediment transport fluxes $q$ are quantified by multiplying sediment concentration $c$ and horizontal cross-shore velocity $u$ :

$$
q=\rho_{s} u c
$$


where $\rho_{s}$ is the sediment density $\left(\rho_{s}=2650 \mathrm{~kg} / \mathrm{m}^{3}\right)$. Figure $8 \mathrm{a}$ shows the time series of the sediment transport profiles. Although close to the bed the flow is characterized by relatively small velocities, the largest sediment fluxes are observed within the sheet flow layer where high sediment concentrations occur (exceeding $400 \mathrm{~kg} /\left(\mathrm{m}^{2} \mathrm{~s}\right)$ ). In figure $8 \mathrm{~b}$, the sediment concentration fluxes are plotted with respect to the (fluctuating) sandy bottom location. This highlights how the sheet flow layer thickness fluctuates during the wave action. The sheet flow layer is likely to exceed $2 \mathrm{~cm}$ during uprush and can reach up to $4 \mathrm{~cm}$ for the more energetic events. The maximum sheet flow layer thickness observed during backwash is usually smaller than that observed during uprush.

Cross-shore suspended load $Q_{\text {susp }}$ and sheet flow load $Q_{s f}$ sediment transport are obtained by integrating the corresponding sediment transport fluxes over the vertical:

$$
\begin{gathered}
Q_{\text {susp }}=\rho_{s} \int_{\delta}^{O B S_{4}}(u c) d z \\
Q_{s f}=\rho_{s} \int_{0}^{\delta}(u c) d z
\end{gathered}
$$

where $O B S_{4}$ is the vertical location of the highest OBS. The total sediment transport load $Q_{\text {tot }}$ is the sum of $Q_{\text {susp }}$ and $Q_{s f}$ :

$$
Q_{t o t}=Q_{\text {susp }}+Q_{s f} .
$$

Figure 9b shows the time series of the total sediment transport load $Q_{t o t}$. The sediment transport load peaks occur at the bore arrivals and are on the order of $40 \mathrm{~kg} /(\mathrm{ms})$ for the most energetic events. In general terms, the energetic events with large free surface displacements generate large onshore-directed sediment transport load peaks; however, it seems that also the sequence of incoming bores can play a role with the interaction between energetic backwash and uprush potentially having a significant impact on sediment transport (see swash event starting at $3400 \mathrm{~s}$ ). Offshore-directed (negative) sediment transport load peaks occur during the backwash and are smaller than the onshore loads. It is worth mentioning that due to the difficulties in collecting reliable near-bed velocity and concentration measurements at the late stages of backwash, when the water depth becomes increasingly shallow, the negative sediment transport load peaks are likely to be underestimated. Figure $9 \mathrm{c}$ shows the time series of suspended and sheet flow sediment transport loads. Suspended sediment transport loads represent the major contribution of the 
total load during uprush phases of swash. The peak of sediment transport uprush load contribution varies between 2 and 5 times the contribution of the sheet flow load. However, during backwash the suspended and sheet flow sediment transport loads are similar with a pattern of increasing importance of the sheet flow transport observable at the backwash end of energetic events.
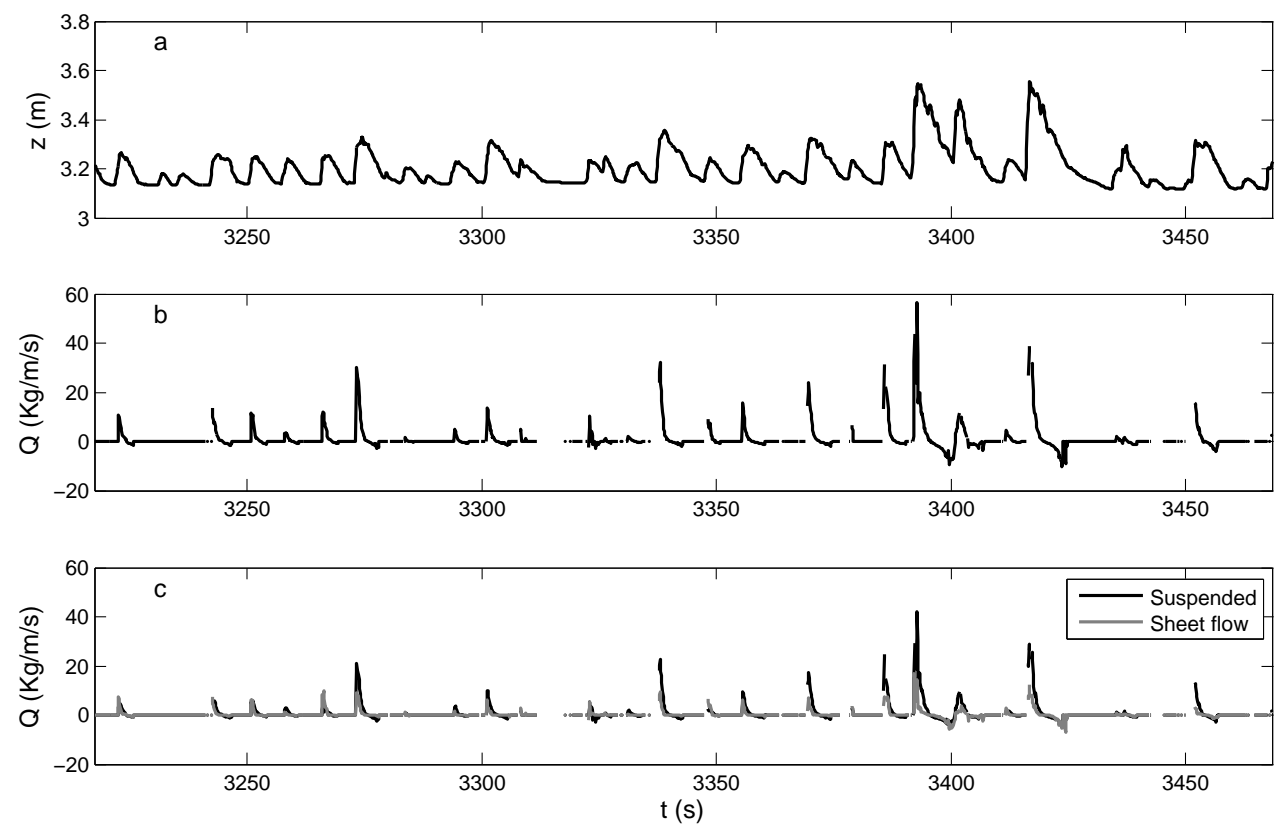

Figure 9: Time series of sediment transport. Free surface elevation (a); total sediment transport (b); suspended (black line) and sheet flow (grey line) sediment transport (c).

Figure 10 shows the (volumetric) cumulative sediment transport loads $Q_{c}$ :

$$
Q_{c}=\frac{1}{\rho_{s}} \int_{0}^{T}\left(Q_{\text {susp }}+Q_{s f}\right) d t
$$

where the time $T$ is considered as the total duration of the run case in this work (one hour). The uprush (-on) and backwash (-off) contributions to the total sediment transport are indicated separately in the figure. The total cumulative sediment transport is $1.1 \mathrm{~m}^{3} / \mathrm{m}$ and is made up of $0.8 \mathrm{~m}^{3} / \mathrm{m}$ contribution from suspended sediment transport $Q_{c-s u s p}$ and $0.3 \mathrm{~m}^{3} / \mathrm{m}$ contribution from sheet flow sediment transport $Q_{c-s f}$. This reflects the dominance of suspended transport over sheet flow under uprush $\left(Q_{c-s u s p-o n}\right.$ is 
more than double $Q_{c-s f-o n}$ ) already observed in figure $9 \mathrm{c}$. On the other hand, during the backwash the suspended and sheet flow contribute similarly to the offshore sediment transport. The present results are consistent with Puleo et al. (2015) who found uprush phases of swash dominated by suspended sediment transport. During backwash under regular wave forcing characterized by a long wave period, Puleo et al. (2015) reported a dominance of sheet flow over suspended sediment transport, whereas here the two contributions are on the same order of magnitude. A simple continuity principle leads to the consideration that, since the net change $\Delta S$ in the total amount of sediment shoreward of the swash rig location is driven by the sediment transport fluxes across the same swash rig location, it should match the volumetric cumulative sediment transport load $Q_{c}$ (disregarding longshore non-uniformities):

$$
\Delta S=(1-n) \int_{x_{s}}^{x_{\infty}} \Delta s_{b}(x) d x \sim Q_{c}
$$

where $x_{s}$ is the swash rig location $(89.6 \mathrm{~m}), x_{\infty}$ is the shoreward location of the beach that is located uphill the maximum runup and does not experience any changes during the wave action, $\Delta s_{b}(x)$ is the change of the elevation of the sandy bed between the end and the beginning of the run case, $n$ is the porosity $(n=0.4)$. The BLS data provide a change $\Delta S$ of total amount of sediment shoreward of the swash rig during the run case of $0.005 \mathrm{~m}^{3} / \mathrm{m}$ which is two order of magnitude smaller than the cumulative sediment transport load $Q_{c}$ of $1.1 \mathrm{~m}^{3} / \mathrm{m}$. It is important to note that a perfect match is unlikely expected mainly due to small longshore non-uniformities and lacking of velocity data under small bores. However, long-shore loads represent only a small fraction (3\%) of cross-shore loads (not shown) and the fact that Qc is two orders of magnitude larger than the change in the beach profile highlights the overestimation of the onshore sediment budget calculated via sediment transport integration. This is likely to be the consequence of two issues related to sediment trasport data collection. Firstly, it is worth mentioning the difficulties that velocity and concentration gauges mounted on the swash rig have on recording offshore sediment transport during the late phases of backwash when water depths are small. Secondly, the measured suspended sediment concentrations may have been spuriously augmented by the presence of air bubbles during uprush (Puleo et al., 2006), see section 4 where this issue is further discussed. Finally, although of secondary importance, additional uncertainties are brought by the assumptions adopted in 
the reconstruction of the velocity and sediment concentration profiles where measurement gaps are present.

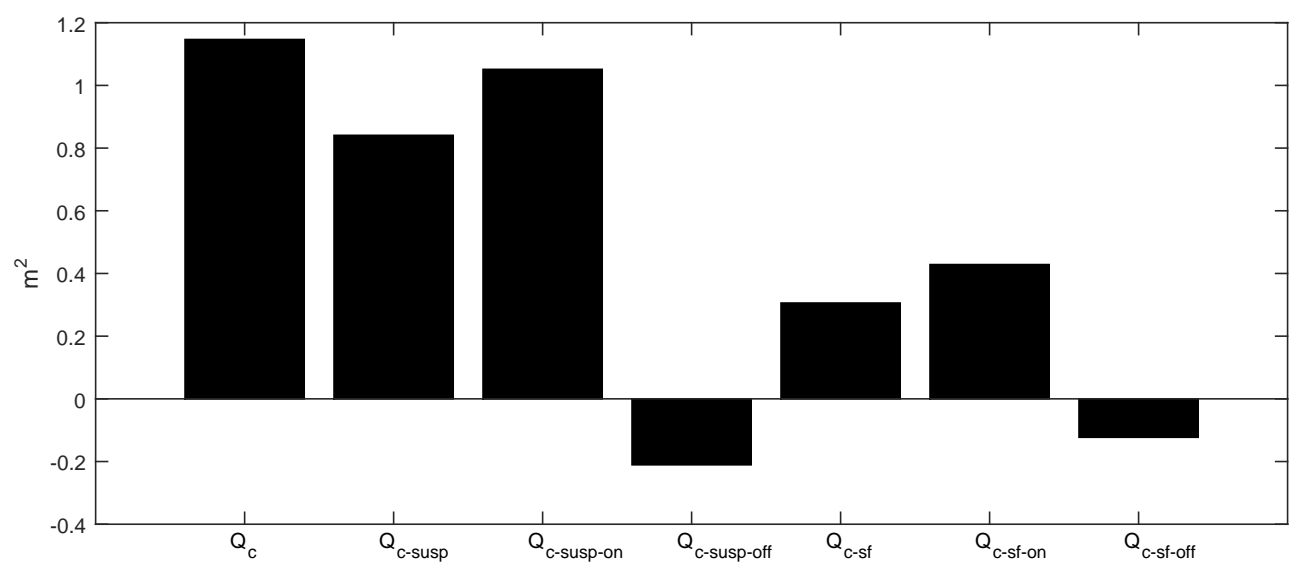

Figure 10: Cumulative sediment transport loads. $Q_{c}$ : total sediment transport load; $Q_{c-s u s p}$ suspended; $Q_{c-s u s p-o n}$ suspended during uprush; $Q_{c-s u s p-o f f}$ : suspended during backwash; $Q_{c-s f}$ sheet flow; $Q_{c-s f-o n}$ : sheet flow during uprush; $Q_{c-s f-o f f}$ : sheet flow during backwash.

The cumulative sediment transport profile $q_{c}$ is obtained by integrating the sediment transport rates at different elevations over time:

$$
q_{c}=\int_{0}^{T} q d t
$$

Figure 11a shows the uprush and backwash cumulative sediment transport profile for a vertical system $z_{b}$ with the origin at the (fluctuating) bottom. The largest sediment transport rates are observed close to the bottom at 0.006 and $0.004 \mathrm{~m}$ for uprush and backwash, respectively. During uprush, the sediment transport profile exhibits a gradual decrease towards upper elevation, whereas the backwash sediment transport diminishes rapidly between 0.005 and $0.01 \mathrm{~m}$ from the bottom and then it takes small values upwards. In figure 11c the uprush and backwash sediment transport profiles are displayed separately with the vertical coordinate system normalized by the instantaneous sheet flow layer thickness $\delta$. As a result of the multiplication between the linear velocity profile and the linear concentration profile observed within the sheet flow layer, the peak of both the uprush and backwash profiles occurs at the middle sheet flow layer at $0.5 z / \delta$ with a rapid decrease immediately 
upwards until $\sim 1.1 z / \delta$ above the top of the sheet flow layer. Above the sheet flow layer, the uprush profile is characterized by sediment transport rates of $\sim 20000 \mathrm{Kg} / \mathrm{m}^{2}$, one order of magnitude larger than the backwash profile. Figures $11 \mathrm{~b}$ shows the net and gross cumulative sediment transport profiles. The gross cumulative sediment transport profile is defined as:

$$
q_{c g}=\int_{0}^{T}|q| d t
$$

As a result of the larger uprush values, the net sediment transport profile is strictly positive with a maximum localized at $0.008 \mathrm{~m}$ and a gradual decrease towards higher locations. On the other hand, the peak of the gross sediment transport profile is at $0.004 \mathrm{~m}$. In figure $11 \mathrm{~d}$ the net and gross profiles are shown with the vertical coordinate system normalized by the sheet flow layer thickness $\delta$. Whereas the gross sediment transport profile is characterized by a peak at $0.5 z / \delta$, the net sediment transport profile does not present a sharp peak due to the similar vertical peak position for uprush and backwash transport (see figure 11c) with the maximum values distributed along the upper half of the sheet flow layer. Overall, figure 11 shows a clear dominance of cumulative sheet flow sediment fluxes over cumulative suspended sediment fluxes with the peak of cumulative sediment transport profiles appearing at the middle of the sheet flow layer.

\subsection{Event-based hydrodynamics and sediment transport}

This section deals with the beach face response induced by individual swash events. In order to do this, the location of the moving shoreline (runup) is identified using BLS data by assuming that the BLS signal does not change for a dry exposed bed. Individual swash events are separated by time intervals in which the runup stays at least $1 \mathrm{~s}$ lower than the swash rig location implying that the beach face in the swash zone is dry and thus its elevation is measurable by BLS. Figure 12a shows the runup oscillations highlighted over the BLS signal in the swash zone. The swash event durations range from the incident wave period of $8 \mathrm{~s}$ up to $100 \mathrm{~s}$ for those events constituted by a large number of runup peaks. The maximum horizontal runup excursion measured during the run is $17 \mathrm{~m}$. Figure $12 \mathrm{~b}$ shows the BLS signal at the swash rig position. It can be noted that before the start of a swash event the BLS signal remains constant implying that the previous backwash has cleared the beach bed (Masselink et al., 2009). The morphological changes in 

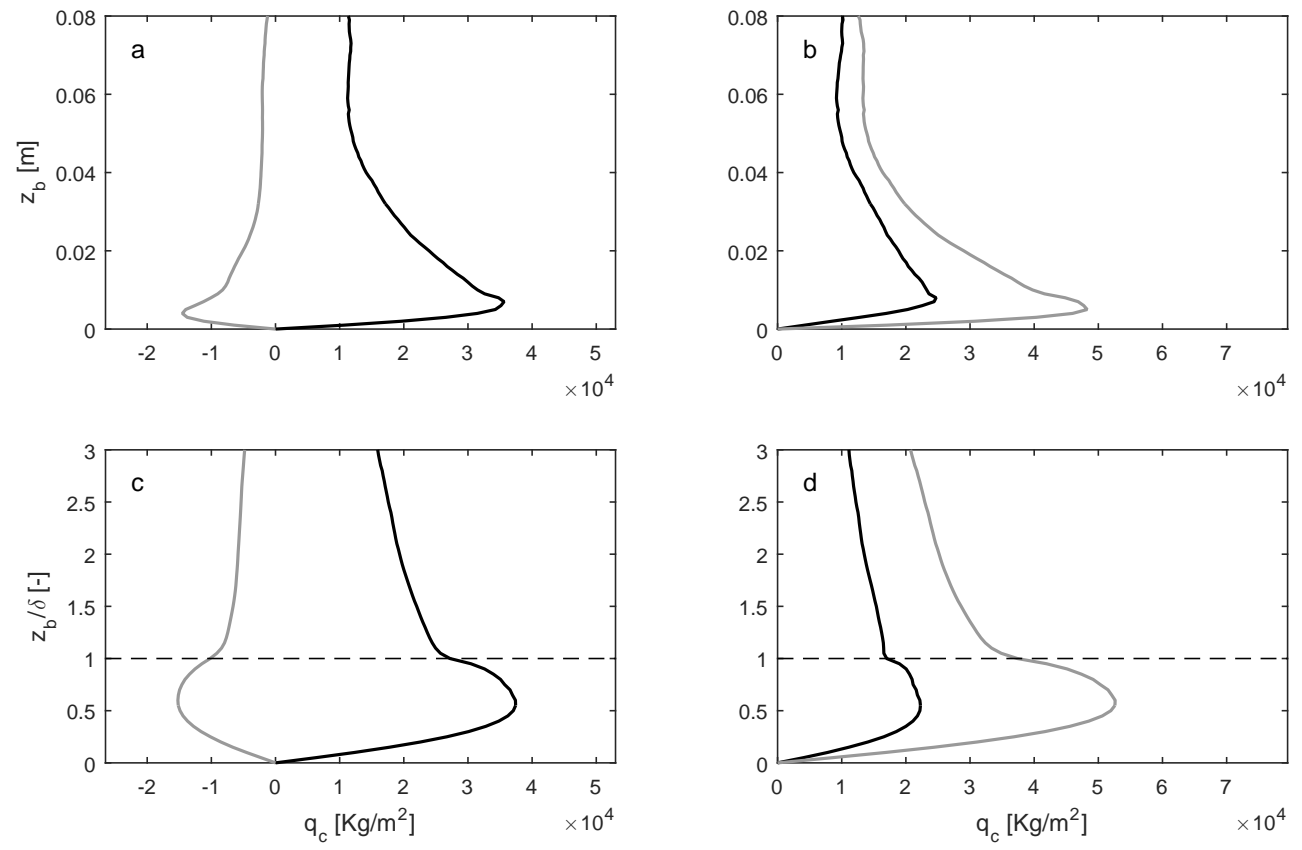

Figure 11: Cumulative sediment transport profiles. a) Uprush (black line) and backwash (grey line); b) Net (black line) and gross (grey line); c) Uprush (black line) and backwash (grey line) with vertical coordinate system normalized by the sheet flow layer thickness $\delta$; d) Net (black line) and gross (grey line) with vertical coordinate system normalized by the sheet flow layer thickness $\delta$. The horizontal dashed line in c) and d) is the location of the top of the sheet flow layer. 
the swash zone $\Delta S$ for each event are plotted in figure 12c. The fourth panel of figure 12 shows the event-induced local bed elevation changes $\Delta s_{b}$ in the swash zone. It can be noticed the existence of events leading to erosion (or deposition) over the entire swash zone and events leading to both deposition and erosion in different parts of the swash zone. Due to the combined erosion and deposition over different parts of the swash zone some events that are characterized by small net morphological changes can be responsible for large gross changes (see for instance the event starting at 3310 s). Gross morphological changes $\Delta S_{g}$ are defined here as:

$$
\Delta S_{g}=(1-n) \int_{x_{s}}^{x_{\infty}}\left|\Delta s_{b}(x)\right| d x .
$$

The event-induced net profile changes in the swash zone $\Delta S$ are compared with the event-integrated sediment transport values $Q_{e v}$ in figure 13. $Q_{e v}$ is the total sediment transport integrated over the duration of the event $T_{e}$ :

$$
Q_{e v}=\frac{1}{\rho_{s}} \int_{0}^{T_{e}}\left(Q_{\text {susp }}+Q_{s f}\right) d t
$$

As a consequence of the issues associated with time-integrated sediment transport measurements (lack of late backwash measurements and possible overestimation of uprush suspended loads) already commented on, the majority of integrated sediment transport values are positive. On the other hand the net profile changes are distributed around 0 with values ranging between -0.023 and $0.025 \mathrm{~m}^{3} / \mathrm{m}$. Swash events induce morphological changes in the order of $0.01 \mathrm{~m}^{3} / \mathrm{m}$ that are usually smaller than the integrated sediment transport reflecting the results obtained in section 3.1 for the entire run duration. Correlations between integrated sediment transport values and morphological changes are weak giving a $r^{2}$ of 0.23 with a standard deviation of the error $E=0.0115 \mathrm{~m}$. This result may be related to the lack of measurements during the backwash phase due to the small water depths and the emergence of OBS, EMCM and ADVP. In an attempt to better address offshore sediment transport, the flow velocities during backwash are extended by assuming that its last measured value remain constant until the end of the event. This is equivalent to assume that the gravitational and friction forces are in balance at the late backwash. Moreover, the concentration above the sheet flow layer are extended up to the free surface by using a exponential profile starting at the top of the sheet flow layer where CCP data are available. 

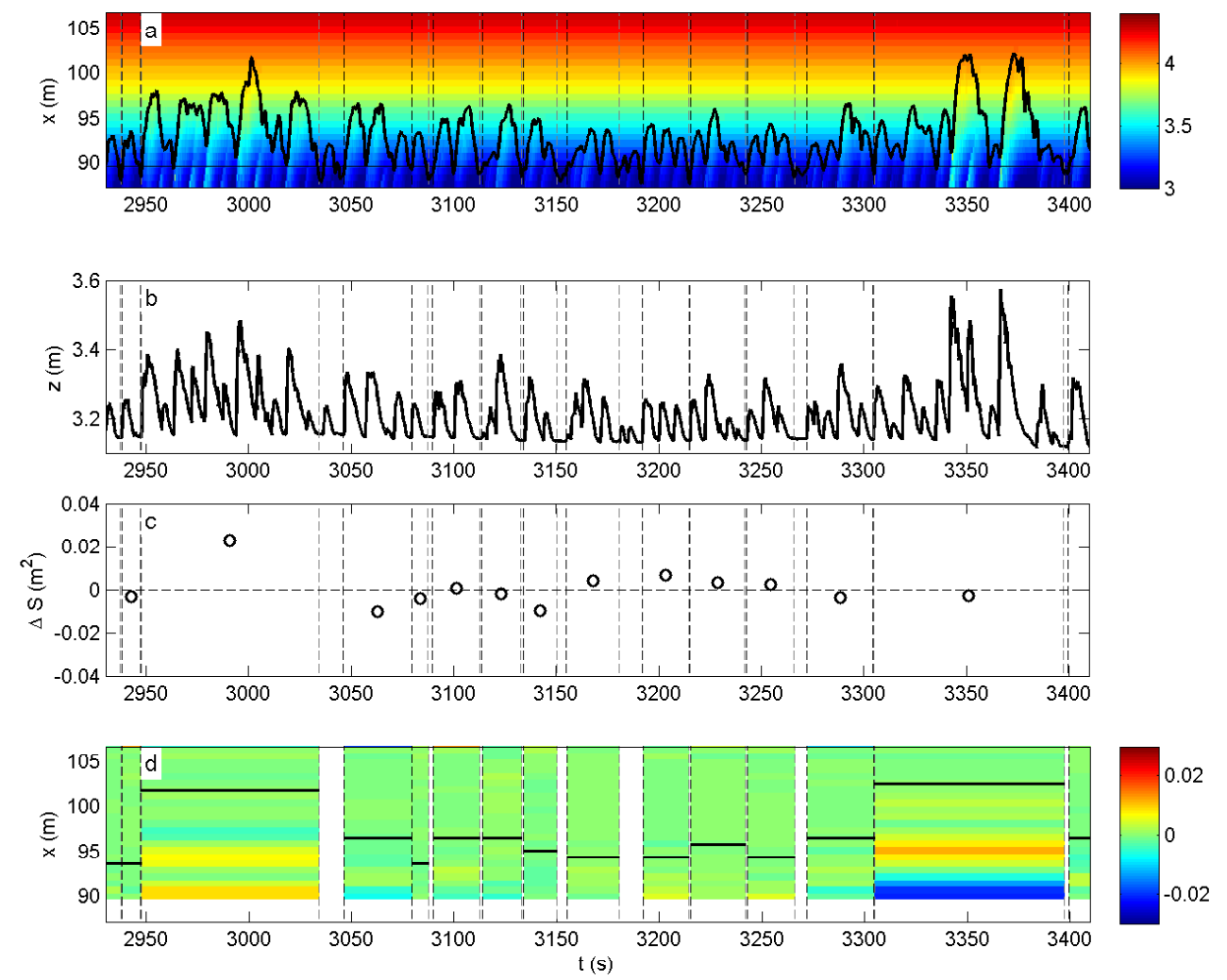

Figure 12: a) BLS-detected elevation across the swash zone in $\mathrm{m}$. The black solid line indicates the moving shoreline position (runup). Vertical dashed lines indicate the swash events and horizontal dashed line represents the swash rig location. b) BLS signal at the swash rig location. c) Change in the total amount of sediment $\Delta S$ shoreward of the swash station in $\mathrm{m}^{2}$. d) Local changes of bed elevation $\delta s_{b}$ across the swash zone in $\mathrm{m}$. Horizontal solid lines in (d) represent the maximum runup extension during each event. 
The integrated sediment transport values $Q_{e v}$ (extended) calculated with the extended backwash are in general smaller than those calculated just with the measurements but still larger than the net profile changes provided by BLS. The application of the backwash extension procedure slightly improves the correlation between $\Delta S$ and $Q_{e v}$ to $r^{2}=0.26$ and brings a reduction of the standard deviation of the error to $E=0.0092 \mathrm{~m}$.
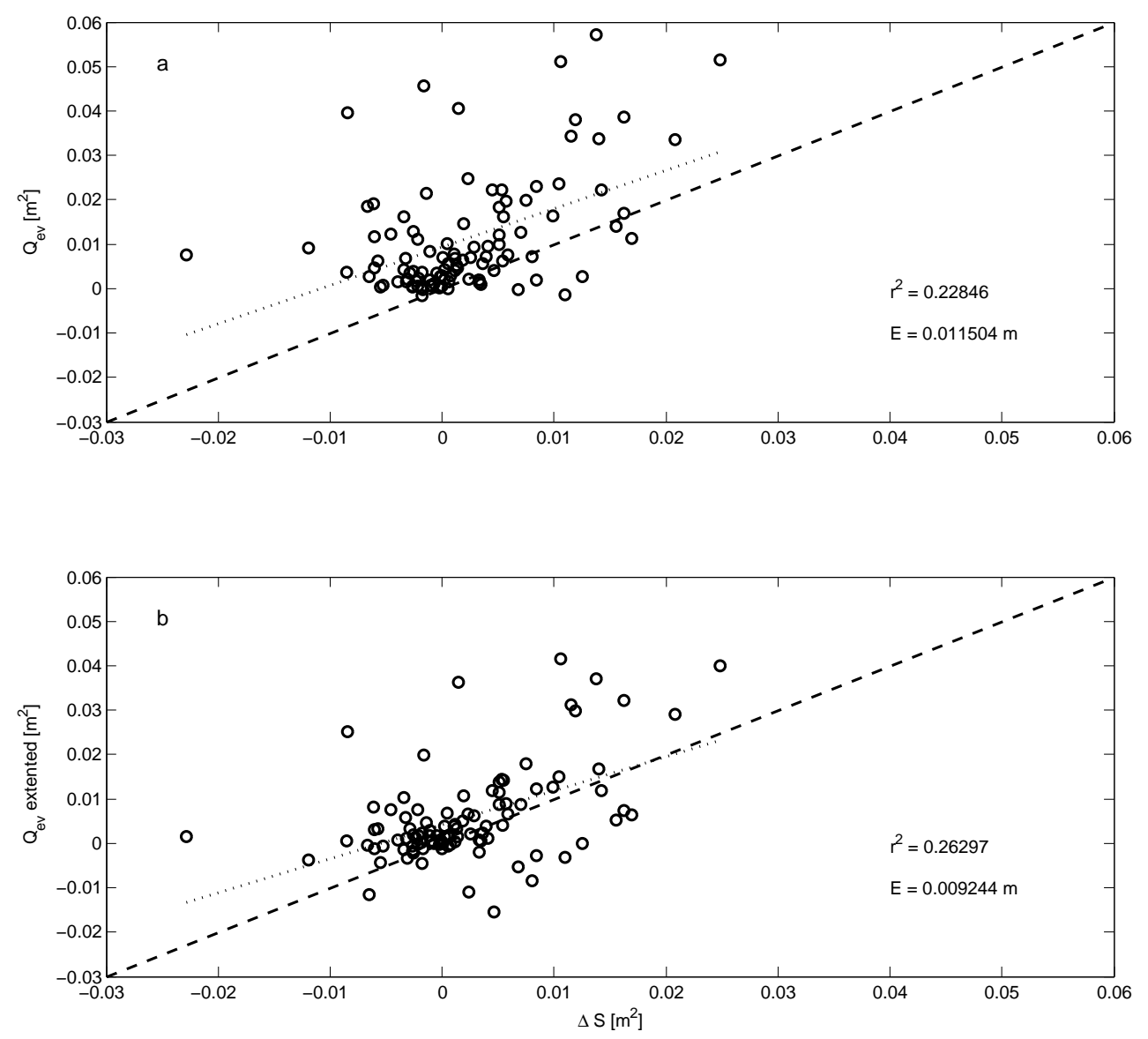

Figure 13: Comparison between net swash profile change $\Delta S$ and integrated sediment transport $Q_{e v}$ on a event by event basis. In (b) the integrated sediment transport values include the backwash extension. Dotted lines indicate the linear regression fitting.

In order to investigate the link between morphological changes in the swash zone over the time scale of individual swash events and runup flow characteristics, table 1 summarizes the correlation coefficients $r^{2}$ between 
the net and gross as well as the strictly positive and negative swash profile changes and runup parameters. The runup parameters on an event-scale basis taken into account are: maximum runup extension (horizontal distance between the rig location and the highest runup peak), maximum uprush extension (maximum horizontal distance between a runup trough and the following runup peak), maximum backwash extension (maximum horizontal distance between a runup peak and the following runup trough), duration, number of peaks, asymmetry and the beach slope in the swash zone $\beta$. Runup asymmetry As is calculated as (Elgar and Guza, 1985):

$$
A s=\frac{\overline{I(H)^{3}}}{{\overline{R^{2}}}^{1.5}}
$$

where $I(H)$ denotes the imaginary part of the Hilbert transform of the runup $R$ and the overline indicates the time-average over the swash event duration. It can be observed that net swash profile changes are poorly correlated with all runup parameters. This seems associated with the fact that energetic runup events are responsible for both large erosion and accretion but the direction of the sediment transport is still difficult to predict. For the same reason gross swash profile changes are relatively highly correlated with runup parameters. In particular, the highest correlation is found between gross swash changes and maximum runup extensions due to the high energy available to bring sediment into suspension during larger swash events. Finally, runup asymmetry does not seem to play any significant role in determining morphological changes.

Taking advantage of the BLS array configuration, the correlations between runup parameters and morphological changes can be recalculated over the whole swash zone. Here, the runup event identification procedure is performed for the 9 cross-shore locations measured by a BLS sensor between the rig location $(x=89.6 \mathrm{~m})$ and $96.1 \mathrm{~m}$. We refer to these locations as base locations. Moving shoreward up to $91.7 \mathrm{~m}$, the number of detected events over the run increases as they are characterized by smaller durations and a lower number of individual peaks in each event. More shoreward, the number of events starts to decrease as there are progressively few events that reach the swash base locations. Figure 14 shows $r^{2}$ calculated between the morphological changes and the runup extension (black line) and between the morphological changes and the swash bed slope (grey line). The runup extension is chosen because it provides the highest correlation especially with gross 

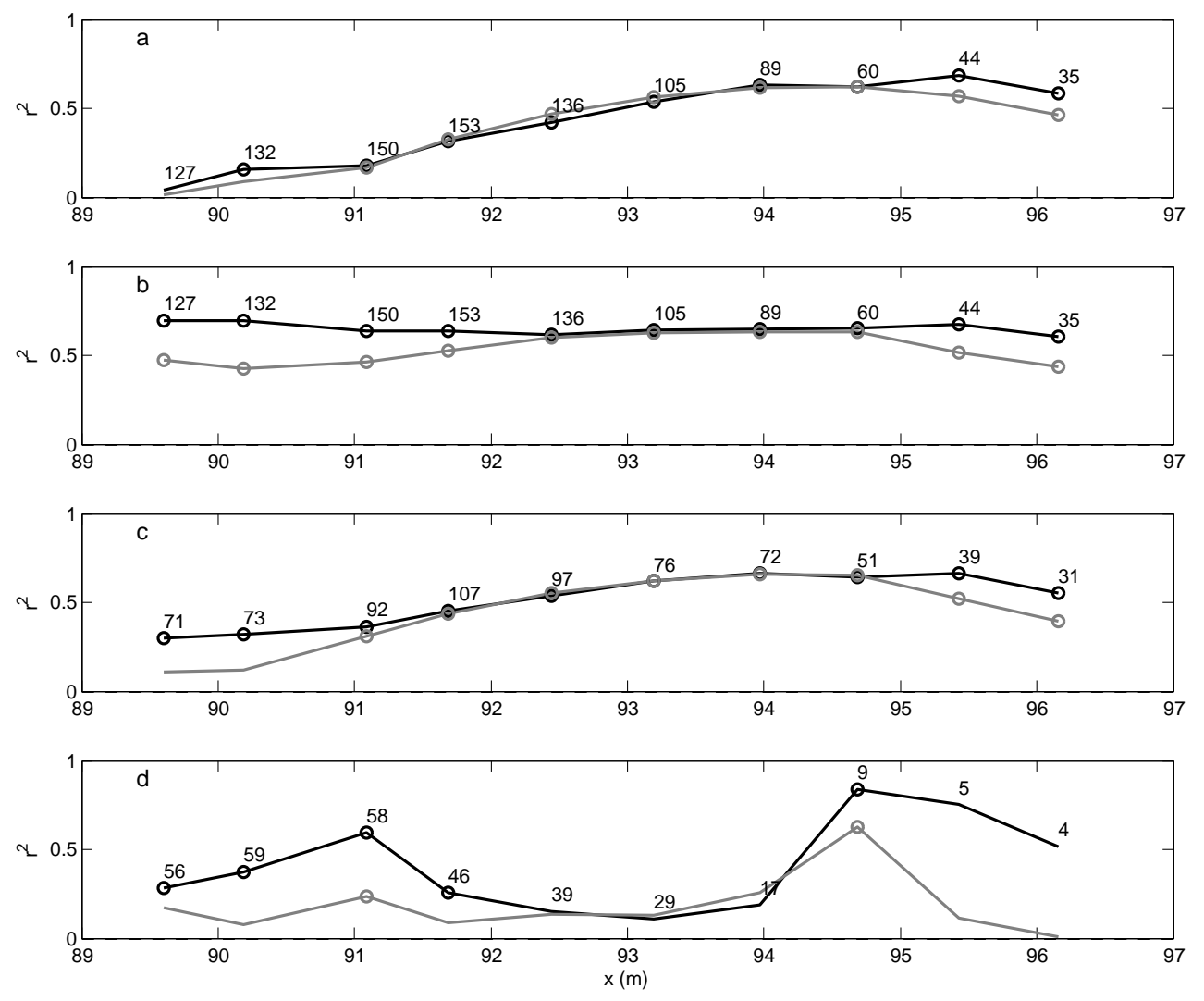

Figure 14: Squared correlations coefficients $r^{2}$ between morphological changes and runup extension (black) and between morphological changes and $\beta$ (grey) as a function of the cross-shore distance. Morphological changes considered include: net (a), gross (b), positive (c) and negative (d) profile changes. The circles indicate the significant $r^{2}$ (significant at the $95 \%$ ). The number of events are shown above the lines. 


\begin{tabular}{ccccc}
\hline & Net & Gross & Positive & Negative \\
\hline Max runup & 0.041 & $\mathbf{0 . 6 9 3}$ & $\mathbf{0 . 2 9 8}$ & $\mathbf{0 . 2 8 1}$ \\
Max uprush & 0.032 & $\mathbf{0 . 5 3 9}$ & $\mathbf{0 . 2 0 7}$ & $\mathbf{0 . 1 9 5}$ \\
Max backwash & 0.033 & $\mathbf{0 . 5 9 7}$ & 0.067 & 0.182 \\
Duration & 0.053 & $\mathbf{0 . 4 5 1}$ & $\mathbf{0 . 4 0 5}$ & $\mathbf{0 . 2 2 1}$ \\
N. of peaks & 0.038 & $\mathbf{0 . 3 4 7}$ & $\mathbf{0 . 3 4 8}$ & $\mathbf{0 . 2 1 6}$ \\
Asymmetry & 0.014 & 0.042 & 0.068 & 0.067 \\
$\beta$ & 0.011 & $\mathbf{0 . 4 7 2}$ & 0.109 & 0.169 \\
\hline
\end{tabular}

Table 1: Squared correlation coefficients $r^{2}$ between morphological changes and flow characteristics. The bold format indicates the significant $r^{2}$ (significant at the $95 \%$ confidence level).

morphological changes; whereas the inclusion of the beach slope allows the investigation of possible functional dependence between the convex beach profile and morphological change. Consistent with the procedure adopted at the swash rig location, the morphological changes are calculated as the amount of sediment accumulated shoreward of the specified base location during each swash event. The correlation $r^{2}$ between runup extension and gross morphological changes is relatively high lying between 0.6 and 0.7 over the entire swash zone. On the other hand, $r^{2}$ for the net changes is low at $x=89.6$ (see also table 1) and it increases shoreward. A similar trend is observed for the $r^{2}$ for the positive events reflecting the fact that the ratio between the number of positive and negative events increases shoreward. When analysing the correlation between the slope and the changes in the profile, it is worth to bear in mind that the correlation coefficient $r$ is negative in this case (the sign is removed once $r$ is squared). The trend of $r^{2}$ for $\beta$ is similar to that observed for the runup extension. This is because of the convex shape of the beach that yields smaller swash slopes for the more energetic swash events flowing over larger horizontal distances.

\section{Discussion}

The results presented in sections 3.1, 3.2 and 3.3 highlight how the bed level and the beach profile in the swash zone respond to the forcing imposed by incoming waves. The bed and sheet flow layer fluctuations observed in this study respond to the hydrodynamic forcing following a recognisable pattern 
along the individual swash events. Figures 7 and 8 provide insights of the main patterns of the swash events and the bed changes. During uprush, sediment is brought into suspension and transported onshore (see figure 9) causing a sudden decrease of the bed level; at the same time the top of the sheet flow layer rises as sediment is moved from the bed. The decrease of the bed level as the wave bore hits the swash rig is consistent with the cross-spectral phases tending to $\pi$ for values for frequencies higher than the incoming peak frequency (figure 5). At the end of uprush and during flow reversal, sediment settles down on the bottom and the sheet flow layer tends to become thinner as the hydrodynamic forcing becomes small inducing a bed recovery. As the flow direction turns offshore with progressively increasing velocities during backwash of the energetic events, sediment is moved offshore and the bed level experiences a reduction that occurs more gradually than during uprush. The bed level decrease is accompanied by a growth of the sheet flow layer thickness which appears smoother than that observed during uprush.

Beside the bed level fluctuations induced by the individual swash events, figure 4 shows that the bed motion at the swash rig location is dominated by low-frequency oscillations consistent with previous studies carried out on dissipative beaches (Puleo et al., 2014). The cross-spectral analysis provides negative phases for the lowest spectral frequencies suggesting that the free surface oscillations lag the bed elevations. This can be interpreted as a feedback mechanism in which the hydrodynamic-generated bed fluctuations lead to slow-varying oscillations in the free surface by imposing the lower boundary to the water flow.

For short (swash event duration) time scales, low correlations are found between the integrated sediment transport $Q_{e v}$ at the swash rig location and the volumetric change of the beach $\Delta S$ shoreward of the swash rig position. A likely explanation for this result can be found in the difficulty in measuring sediment transport in the late backwash when water depths are shallow. However, the artificial extension of the offshore sediment transport beyond the measured backwash phases brings only a small increase in the correlation which raises from $r^{2}=0.23$ to $r^{2}=0.26$ suggesting that the lack of late backwash measurements is not enterely responsible of this observed unbalanced sediment budget. Alternatively, although the cleaning procedure described in section 2.2 was carried out with the main purpose of removing unreliable ADVP measurements associated with the presence of air bubbles, the suspended sediment flux could still have been overestimated as a result 
of the effect of air-entrainment on the output OBS voltage. In fact, Puleo et al. (2006) showed that in freshwater the voltage (and the sediment concentration) can be increased by up to $25 \%$ in the presence of air bubbles. The influence of air entrainment on OBS data measurements and therefore on suspended sediment fluxes may have affected the analysis of cross-shore sediment flux balance. Finally, the procedure adopted in order to fill the spatial gaps in the water column can bring additional uncertainties in the sediment transport estimation.

The morphological changes that occur on a temporal event-scale are hardly explained in terms of hydrodynamic runup parameters. In fact, relatively high correlations $\left(r^{2}>0.5\right)$ are found only for the gross profile changes implying that the most energetic swash events are indeed able to bring significant morphological changes. However, associating the hydrodynamic runup parameters with net morphological changes has provided poor correlations suggesting that the discrimination between erosive and accretionary is not the direct consequence of local parameters but is likely to be associated to both surf zone processes such as sediment and turbulence advection (Hughes et al., 2007; Alsina et al., 2009) and the existence of equilibrium profile (Larson et al., 2004; Masselink et al., 2009). Further research is needed to investigate these hypotheses.

Extending the time-scale of the analysis, these experimental results suggest that the net swash profile change over the entire run is a small value when compared with the swash profile changes yielded by the individual swash events. In fact the net swash changes yielded by individual events range between -0.023 and $0.025 \mathrm{~m}^{3} / \mathrm{m}$, whereas the net profile change over the entire run is only $0.005 \mathrm{~m}^{3} / \mathrm{m}$. Therefore, the beach equilibrium observed in this one-hour long run is actually the result of a balance between relatively large erosive and accretionary events. The significance of this result appears important when morphological changes on relatively large time-scale are predicted by addressing small-scale processes such as event-by-event sediment transport since relatively small errors can accumulate potentially leading to unrealistic results.

\section{Conclusions}

A large-scale laboratory experiment was carried out on a steep coarsesand beach backed by a lagoon. Sediment transport data and bed fluctuations 
were recorded in the lower swash zone with a high spatial and temporal resolution. The main findings are listed here:

1. Bed level motion at the swash rig location is dominated by low-frequency oscillations on the order of $500 \mathrm{~s}$. The bed oscillations at frequencies higher than the incident frequency peak are in antiphase with the free surface elevations implying that the bed level decreases occur during uprush bores. Maximum recorded bed increase and decrease are 0.022 $\mathrm{m}$ and $-0.021 \mathrm{~m}$, respectively.

2. The large sediment concentrations found close to the bottom yield sheet flow sediment transport fluxes to be larger than suspended fluxes. However, once sediment transport fluxes are integrated in the vertical, the suspended loads exceed the sheet flow loads during uprush and are on the same order of magnitude during backwash.

3. The integrated sediment transport provided by velocity and concentration data is much larger than the change of amount of sediment shoreward of the swash station recorded by BLS. This mismatch appears to be related either to an the presence of bore-generated air-entrainment yielding an overestimation of the uprush suspended sediment concentrations or to an underestimation of the offshore sediment transport as a consequence of the difficulties in recording the backwash phase of swash. Attempts to compensate for the latter suggest that the former may be the largest issue.

4. Net swash profile changes shoreward of the measurement location are in general poorly correlated with hydrodynamic runup parameters. Relatively high correlations $\left(r^{2}>0.5\right)$ are found only for the gross profile changes implying that large swash events induce both large accretion and erosion. Determining whether a single swash event will cause erosion or accretion seems to be not associated with local runup parameters.

5. The swash profile experiences a small volumetric change $\left(0.005 \mathrm{~m}^{3} / \mathrm{m}\right)$ over the one-hour long case run. This equilibrium resulting from a balance between events causing relatively large erosion and deposition $\left(\sim 0.02 \mathrm{~m}^{3} / \mathrm{m}\right)$ highlights the difficulty in predicting the nature of net transport direction. 


\section{Acknowledgment}

This work was supported by the Engineering and Physical Sciences Research Council of the UK under grant number EP/K000306/1. The BARDEX II experiments described in this publication were supported by the European Community's 7th Framework Programme through the grant to the budget of the Integrating Activity HYDRALAB IV, contract no. 261520. The academic lead of the BARDEX II project was Gerd Masselink and the Deltares coordinator was Guido Wolters.

\section{References}

Aagard, T., Hughes, M. G., 2006. Sediment suspension and turbulence in the swash zone of dissipative beaches. Marine Geology 228, 117-135.

Alsina, J. M., Falchetti, S., Baldock, T. E., 2009. Measurements and modelling of the advection of suspended sediment in the swash zone by solitary waves. Coast. Eng. 56, 621-631.

Bagnold, R. A., 1956. The flow of cohesionless grains in fluids. Phil. trans. Roy. Soc. London A 249, 235-297.

Caceres, I., Alsina, J., 2012. A detailed, event-by-event analysis of suspended sediment concentration in the swash zone. Cont. Shelf Res. 41, 61-76.

Dohmen-Janssen, C. M., Hanes, D. M., 2005. Sheet flow and suspended sediment due to wave groups in a large wave flume. Cont. Shelf Res. 25 (3), 333-347.

Elfrink, B., Baldock, T. E., 2002. Hydrodynamics and sediment transport in the swash zone: A review and perspectives. Coastal Eng. 45, 149-167.

Elgar, S., Guza, R. T., 1985. Observations of bispectra of shoaling surface gravity waves. J. Fluid Mech. 161, 425-448.

Horn, D., Mason, T., 1994. Swash zone sediment transport modes. Marine Geology 120, 309-325.

Hsu, T., Jenkins, J. T., Liu, P. L.-F., 2004. On two-phase sediment transport: sheet flow of massive particles. Proc. R. Soc. Lond. A 460 (C8), 2223-2250. 
Hughes, M. G., Aagaard, T., Baldock, T. E., 2007. Suspended sediment in the swash zone: heuristic analysis of spatial and temporal variations in concentration. Journal of Coast. Res. 23, 1345-1354.

Hughes, M. G., Masselink, G., Brander, R. W., 1997. Flow velocity and sediment transport in the swash zone of a steep beach. Marine Geol. 138, 91-103.

Lanckriet, T., Puleo, J. A., Masselink, G., Turner, I. A., Conley, D., Bleankisopp, C., Russel, P., 2014. Comprehensive field study of swashzone processes. ii: Sheet flow sediment concentrations during quasi-steady backwash. Journal of Waterway, Port, Coastal, and Ocean Engineering 140, 29-42.

Lanckriet, T., Puleo, J. A., Waite, N., 2013. A conductivity concentration profiler for sheet flow sediment transport. IEEE JOURNAL OF OCEANIC ENGINEERING 38, 55-70.

Larson, M., Kubota, S., Erikson, L., 2004. Swash-zone sediment transport and foreshore evolution: field experiments and mathematical modeling. Marine geology 212, 61-79.

Masselink, G., Evans, D., Hughes, M. G., Russell, P., 2005. Suspended sediment transport in the swash zone on a dissipative beach. Marine geology 216, 169-189.

Masselink, G., Hughes, M., 1998. Field investigation of sediment transport in the swash zone. Cont. Shelf Res 18 (10), 1179-1199.

Masselink, G., Puleo, J. A., 2006. Swash-zone morphodynamics. Cont. Shelf Res. 26 (5), 661-680.

Masselink, G., Ruju, A., Conley, D., Turner, I., Ruessink, B. G., Matias, A., Thompson, C., Castelle, B., Wolters, G., 2015. Large-scale Barrier Dynamics Experiment II (BARDEX II): experimental design, instrumentation, test programme and data set. Coast. Eng.Accepted for publication. DOI: 10.1016/j.coastaleng.2015.07.009.

Masselink, G., Russel, P., Turner, I., Blenkinsopp, C., 2009. Net sediment transport and morphological change in the swash zone of a high-energy 
sandy beach from swash event to tidal cycle time scales. Marine Geology 267, 18-35.

Mori, N., Suzuki, T., Kakauno, S., 2007. Noise of acoustic doppler velocimeter data in bubbly flows. Journal of Engineering Mechanics 133, 122-125.

Nielsen, P., 1992. Coastal Bottom Boundary Layers and Sediment Transport. World Scientific.

O'Donoghue, T., Wright, S., 2004. Concentrations in oscillatory sheet flow for well sorted and graded sands. Coast. Eng. 50, 117-138.

Pugh, F. J., Wilson, K. C., 1999. Velocity and concentration distributions in sheet flow above plane beds. Journal of Hydraulic Engineering 125, $117-$ 125 .

Puleo, J., Lanckriet, T., Conley, D., Foster, D., 2015. Sediment transport partinioning in the swash zone of a large-scale laboratory beach. Coast. Eng.Accepted for publication. DOI: 10.1016/j.coastaleng.2015.11.001.

Puleo, J. A., Beach, R. A., Holman, R. A., Allen, J. S., 2000. Swash zone sediment suspension and transport and the importance of the bore-generated turbulence. J. Geophys. Res. 105(C7), 17021-17044.

Puleo, J. A., Johnson, R. V., Butt, T., Kooney, T. N., Holland, K. T., 2006. The effect of air bubbles on optical backscatter sensors. Marine Geology 230, 87-97.

Puleo, J. A., Lanckriet, T., Blenkinsopp, C., 2014. Bed level fluctuations in the inner surf and swash zone of a dissipative beach. Marine geology 349, 99-112.

Puleo, J. A., Lanckriet, T., Wang, P., 2012. Near bed cross-shore velocity profiles, bed shear stress and friction on the foreshore of a microtidal beach. Coast. Eng. 68, 6-16.

Ruju, A., Conley, D., Masselink, G., Austin, M., Puleo, J., Lanckriet, T., Foster, D., 2015. Boundary layer dynamics in the swash zone under largescale laboratory conditions. Coast. Eng.Accepted for publication. DOI: 10.1016/j.coastaleng.2015.08.001. 
van der A, D., O’Donoghue, T., Ribberink, J., 2010. Measurements of sheet flow transport in acceleration-skewed oscillatory flow and comparison with practical formulations. Coast. Eng. 57, 331-342. 